\title{
Exprimental Study of Atomization Feature of Coaxial Parallel Flow Airspray Nozzle
}

\author{
Yue Li, Jianqin Suo, Yajun Zhu, Zhenxia Liu \\ School of Power and Energy, Northwestern Polytechnical University, Xian, China
}

\begin{abstract}
Plain orifice and direct injector nozzle are increasingly used in advanced combustion chamber. In order to reduce the sensitivity of the single-phase liquid jet to the changes of air flow, another air jet can be added to form a air-liquid two-phase flow. In this paper, the atomization characteristics of the air-liquid two-phase jet during cross-airflow jetting are experimentally studied with optical instruments. The structure of the two-phase flow is to wrap a layer of annular air jet outside the liquid jet.

Experiments show that when the mass flow rates of the annular air and liquid jets are relatively large, the jets will bifurcate and the droplet size will also be significantly different. When the air-liquid ratio continues to increase, the atomization-assisting effect of the annular air will also increase, and the droplet size difference will also decrease.
\end{abstract}

\section{Keywords}

two-phase flow, cross-flow jet, Atomization Feature

Correspondence to: jqsuo@nwpu.edu.cn

\section{Introduction}

Due to the more and more strict requirements of pollutant emission, the combustion chamber of civil aviation engine is developing towards of low condition. The most representative of advanced gas turbine chamber are Rich-burn Quench Lean-burn (RQL), Lean fuel premixed pre-evaporation (LPP) and Lean direct injection combustor (LDI). Among them, the main stage of LPP and LDI combustor adopts the direct airblast atomizer, which is due to the simple structure of the direct airblast atomizer and better atomization under wide working conditions.

LPP combustion chamber [1, 2, 3] allows fuel to be completely mixed with air before the primary zone through fuel vaporization in advance [4,5]. Fuel enters the combustion chamber through plain orifices in the wall to inject the fuel directly into the cross-airflow [6,7]. The liquid jet is broken and mixed with the air through the aerodynamic force generated between the high-speed air flow and the fuel jet. Direct air atomizer is also used in LDI $[8,9,10]$. Because of the swirling flow of the main mode air, it can be considered that the jet is the process of jet breaking and oil-gas mixing in the cross-airflow.

In the actual combustion chamber, the fuel mass flow is little and the penetration depth is weak under low working conditions. On the other hand, only the cross-airflow atomizes the jet, the effect is always bad, and the droplet size is too large, which will lead to low combustion efficiency. In order to improve the atomization performance of the direct nozzle, an airblast nozzle with annular air $[10,11]$ was experimentally studied in this paper. A layer of annular air coaxial with the liquid jet is wrapped on the outer side of the liquid jet, forming a nozzle structure of air-liquid two-phase jet, which is called coaxial downstream air atomizer. Through experiments, the atomization performance of the nozzle in cross-airflow under different airliquid mass flow ratio was studied, and the atomization performance of the single-phase direct injection nozzle in the transverse air flow was compared, and the coaxial downstream flow 
was obtained. The atomization performance of the air atomization nozzle provides technical support for optimizing the performance of the combustion chamber in the future.

\section{Material and Methods}

In this study, a Winner318A laser particle size meter was used to measure the droplet size of liquid mist, with a range of $4.6 \sim 323 \mu \mathrm{m}$, the measurement accuracy is $0.1 \mu \mathrm{m}$. The resolution of the camera for the fracture of liquid jet and spray field is $7360 \times 4912$ pixels. In this experiment, the pulse laser is used as the light source, and the pulse time is $6 \sim 8 \mathrm{~ns}$. The shooting method is to use the laser as the light source, modulate the frequency of the laser for $15 \mathrm{~Hz}$, and the exposure time of the camera is $1 / 15 \mathrm{~s}$. This ensures that a photograph recording is the picture within $6 \sim 8 \mathrm{~ns}$ of the spray field. The distance of the droplet movement is far less than the diameter in this time period, so a clearer photograph can be taken, as shown in Figure 1. Figure 2 shows a spray field that is taken in conventional manner. The particle size data in this article is obtained by averaging the experimental data from 30 to 35 times measured in $15 \mathrm{~s}$.

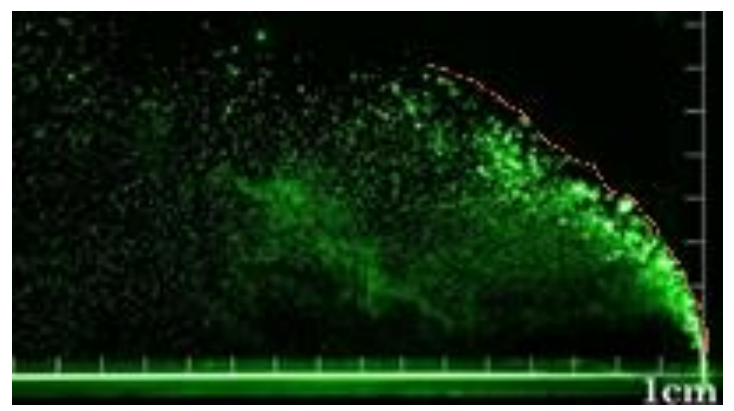

Figure 1. Picture by laser as light source

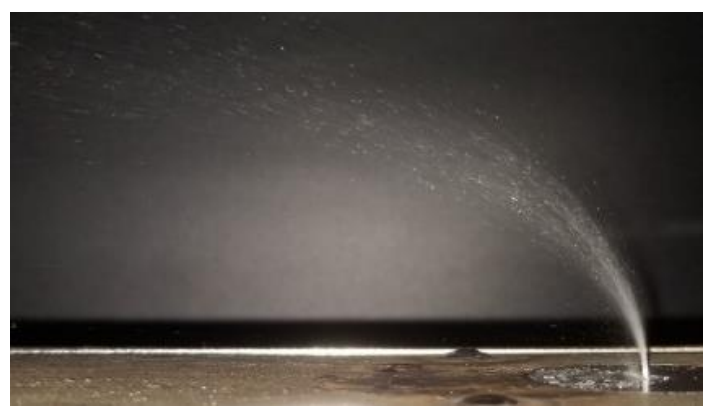

Figure 2. Regular photos

Some researchers have defined the penetration depth of liquid jet in cross-airflow by the distance between the periphery of liquid mist and the bottom surface at the centre section of the jet, for example, literature [12]. This paper also uses this method to define the penetration depth, taking the outer contour of the jet trajectory in the image, example the red dotted line in Figure 1, as the maximum penetration position. The distance from the outermost side of the spray field to the bottom is the penetration depth of the jet trajectory at this transverse position.

The nozzle structure used in the experiment is shown in Figure 3. The diameter of nozzle diameter and liquid passage is $0.5 \mathrm{~mm}$, the inner diameter of annular air passage is $1.5 \mathrm{~mm}$, the outer diameter is $3.5 \mathrm{~mm}$. Figure 4 is a schematic image of light source, air flow and shooting direction. Figure 4 also shows the size of the exit of the cross-airflow, $\operatorname{Re} \in(200000,300000)$.

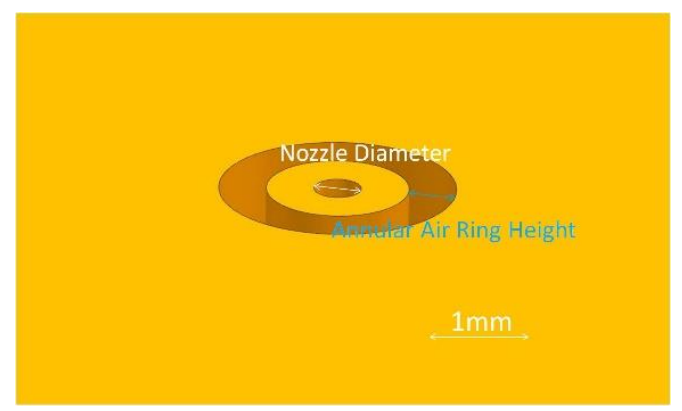

Figure 3. Two-phase jet

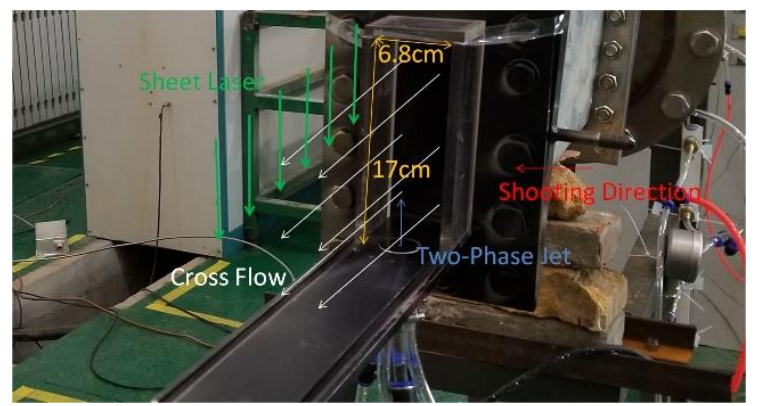

Figure 4. Two-phase jets and cross-airflow schematic image 


\section{Comparison of liquid mist field with and without annular air}

In this experiment, the water mass flow rate is $4.71 \mathrm{~g} / \mathrm{s}$. The pressure of cross-airflow is $100 \mathrm{kpa}$, the velocity of cross-airflow is $35.9 \mathrm{~m} / \mathrm{s}$, and the temperature of cross-airflow is $10^{\circ} \mathrm{C}$. When there is no annular air, the liquid mist image of liquid jet is shown in Figure 5. This experimental study made $2.97 \mathrm{~g} / \mathrm{s}$ annuler air mass flow rate as the stand condition. Figure 6 is the image of liquid mist under the stand condition. Compared with the image without annular air, the most significant difference lies is the phenomenon of "bifurcation" in the liquid mist field as described in references [13] and [14]: there are a large number of droplets in the lower part of the jet trajectory, the distribution range of the liquid mist is obviously wider, and the atomization effect is better.

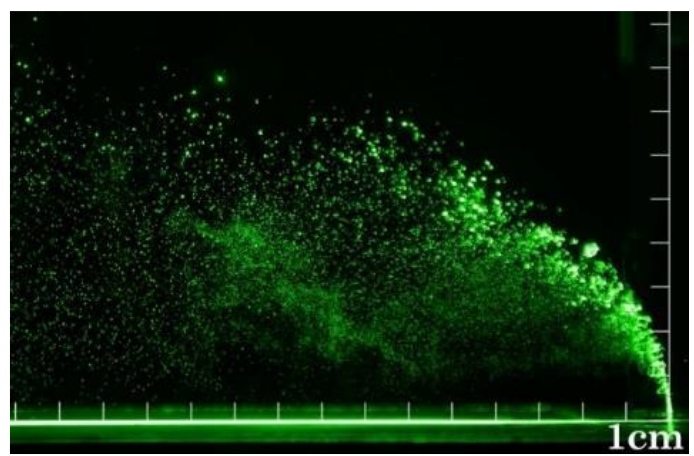

Figure 5. Atomization of air liquid jet without annular assisted atomization

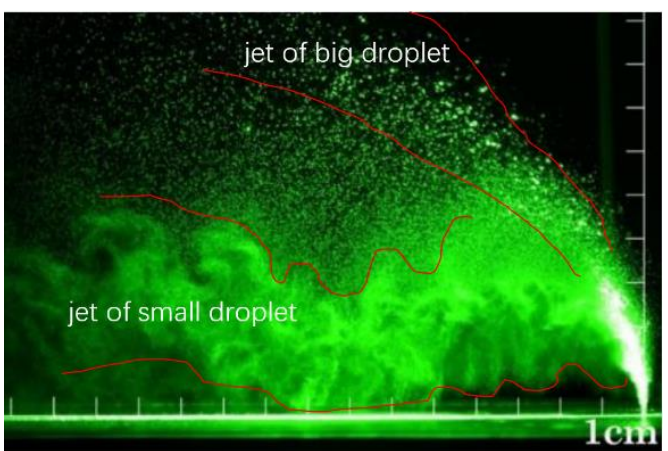

Figure 6. Spray image of water jet with $2.97 \mathrm{~g} / \mathrm{s}$ mass flow rate annular air

In this paper, the liquid mist field with annular atomizing air is divided into four regions as shown in Figure 7.

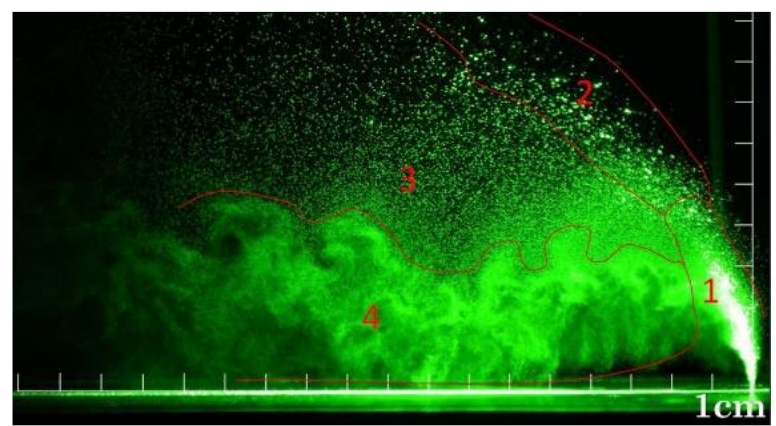

Figure 7. Four zones of two-phase jet in spray filed

Zone I is the area where the jet is initially developed after it is jet from the nozzle. The jet is not broken completely, a very small number of droplets are separated from the main stream, and the liquid still exists mainly in the form of jet;

Zone II is the extension zone of jet trajectory, and the droplets in this zone continue to move almost according to the extension line of jet trajectory before breakup. In this region, the droplet diameter is large, the atomization effect is poor;

Zone III is located in the lower part of the Zone II, which is fan-shaped, and its apex is close to the breakup point of the jet. The droplet size in this region decreases significantly from top to bottom, and the droplet number concentration increases gradually;

Zone IV is at the bottom of the liquid mist field, and the atomization efficiency is the best. From the distribution of droplets, it can be seen that most of these small droplets come from the liquid jet before breaking, and are directly separated from the surface of the jet; 


\section{Influence of air liquid mass flow ratio on atomization of nozzle}

The influence of air-liquid mass flow ratio (ALR $\left.=\frac{\text { annular air mass flow rate }}{\text { liquid mass flow rate }}\right)$ on atomization was studied by changing the mass flow rate of annular air. The mass flow rate of annular air selected in the test is shown in Table 1, and the image of liquid jet atomization with various ALR is shown in Figure 8

Table 1. Annular air flow rate of each working condition

\begin{tabular}{c|ccccccccccccccc}
\hline $\begin{array}{c}\text { Air mass flow } \\
(\mathrm{g} / \mathrm{s})\end{array}$ & 0.346 & 0.432 & 0.634 & 0.754 & 0.823 & 0.954 & 1.27 & 1.44 & 1.95 & 2.37 & 2.98 & 3.56 & 4.48 & 5.26 & 7.54 \\
\hline ALR & 0.062 & 0.092 & 0.134 & 0.160 & 0.174 & 0.202 & 0.268 & 0.305 & 0.414 & 0.488 & 0.630 & 0.753 & 0.950 & 1.11 & 1.60
\end{tabular}

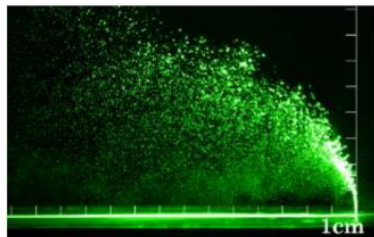

(a) $\mathrm{ALR}=0.062$

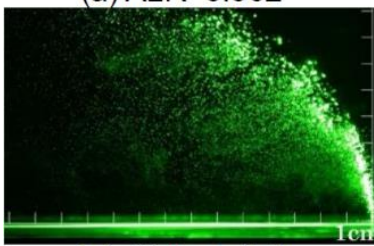

(e) $\mathrm{ALR}=0.174$

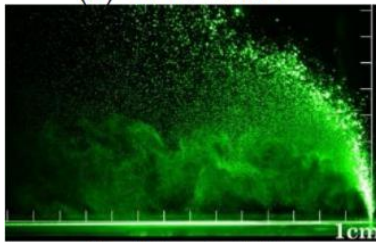

(i) $\mathrm{ALR}=0.414$

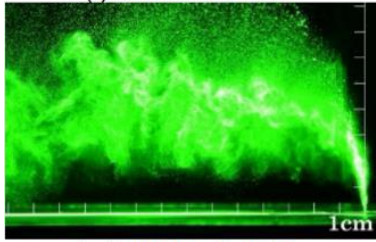

(m) $A L R=0.950$

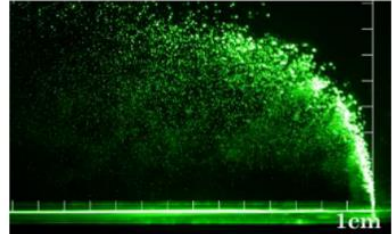

(b) $A L R=0.092$

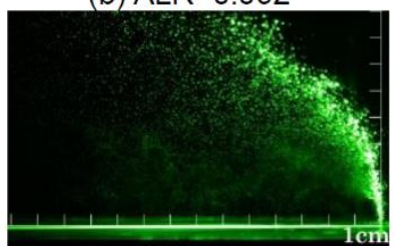

(f) $\mathrm{ALR}=0.202$

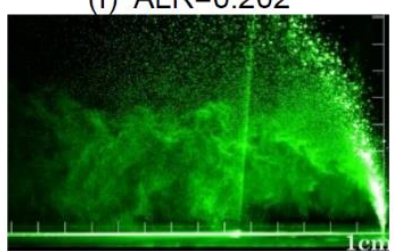

(j) $A L R=0.488$

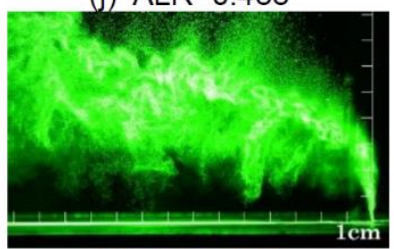

(n) $A L R=1.11 \quad$ (o) $A L R=1.60$

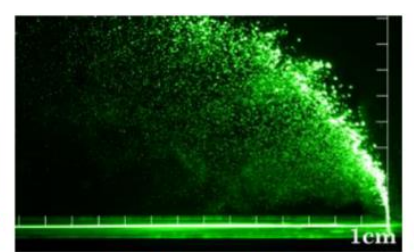

(c) $A L R=0.134$

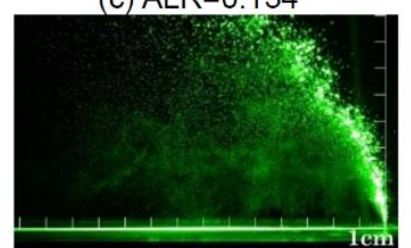

(g) $A L R=0.268$

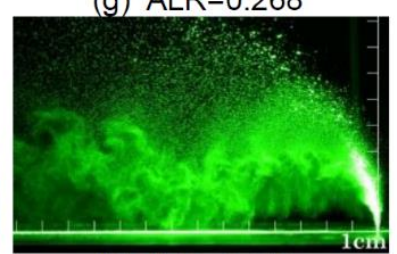

(k) $A L R=0.630$

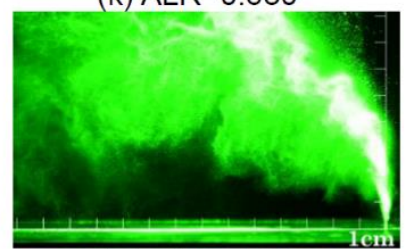

(o) $A L R=1.60$

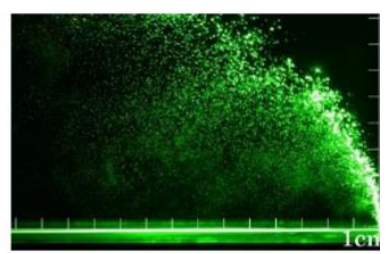

(d) $A L R=0.160$

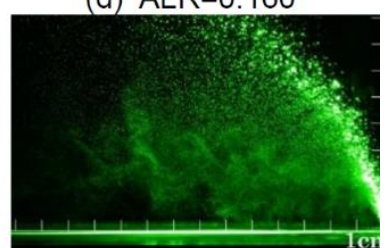

(h) $A L R=0.305$

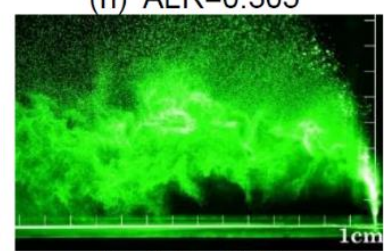

(I) $\mathrm{ALR}=0.753$

When the ALR is in the range of $0.062 \sim 0.305$, the atomization of liquid jet by annular air does not change significantly, and the other four areas do not exist.

When ALR reaches 0.414 , the change of liquid mist field is obvious. The breakup effect of liquid jet is higher and the atomization effect is better. With the increase of annular air, the most obvious change is that the range of Zone I of liquid jet becomes smaller and smaller, while the range of liquid mist formed by small droplets stripped by annular air expands. When ALR reaches 0.630 , the whole unbroken jet is almost wrapped in the liquid mist region. Due to the large mass flow rate of annular air, small size and large number of droplets stripped out, the Zone IV is formed after being blown away by the cross- airflow.

When the ALR exceeds 0.753 , the unbroken part of the liquid jet is completely wrapped in 
the dense small droplets. With the increase of the annular air mass flow, the range of the Zone IV gradually expands until it completely covers the Zone III, and is directly connected with Zone II.

\section{Regional distribution change of spray field}

Taking long exposure photography for 8 spray field with different ALR, the image obtained is the superposition of 90 instantaneous images of liquid jet atomization (the exposure time of the camera is $6 s$, which can reflect the distribution of spray field, as shown in Figure 9.

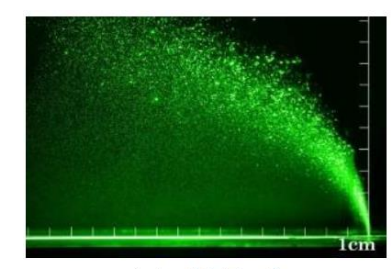

(a) $A L R=0$

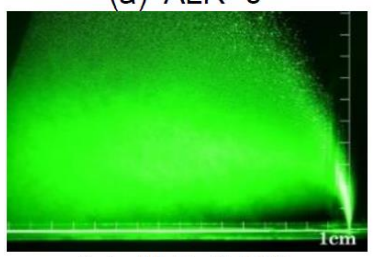

(e) $A L R=0.630$

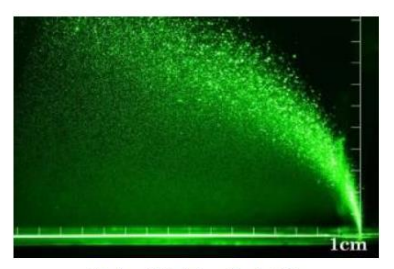

(b) $A L R=0.160$

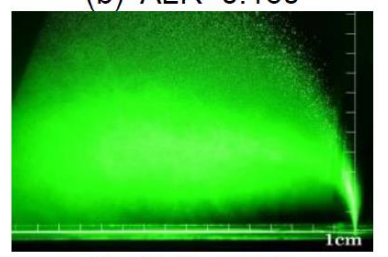

(f) $A L R=0.753$

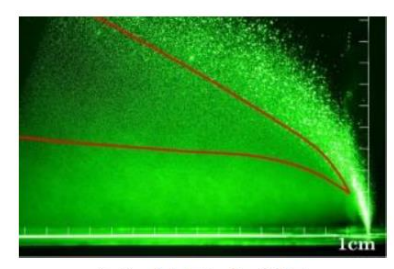

(c) $\mathrm{ALR}=0.305$

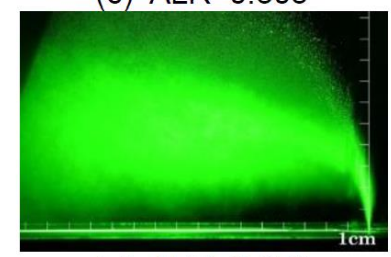

(g) $\mathrm{ALR}=0.950$

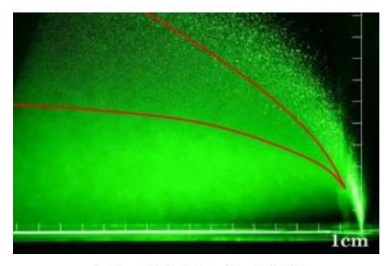

(d) ALR=0.488

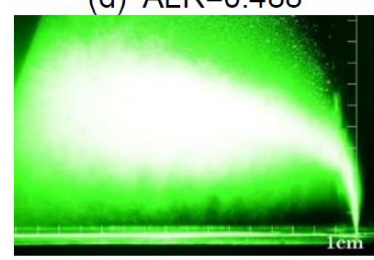

(h) $A L R=1.11$

Figure 9. The distribution of spray field by different ALR

The distribution of spray field is mainly along the direction of jet trajectory, and sparse droplets appear below the jet trajectory. From $A L R=0.630$, the range of the Zone IV gradually expanded and the lower boundary moved up. Because with the increase of the annular air mass flow rate, the air flow velocity is also faster, and the distance of its effect on the liquid jet is longer. Therefore, it is necessary for the liquid jet to move upward for a longer distance in order to weaken the effect of the annular air flow, so that the fine droplets spread backward with the lateral air flow to form a higher height of the Zone IV.

Comparing the penetration trajectories of spray field under working conditions of ALR 0 , $0.160,0.305,0.630$ and 1.11 (Figure.10), it can be seen that the existence of annular air also makes the penetration depth of liquid jet becoming deeper. Because the annular air increases the total momentum of the two-phase jet and help enhancing the penetration ability of the liquid.

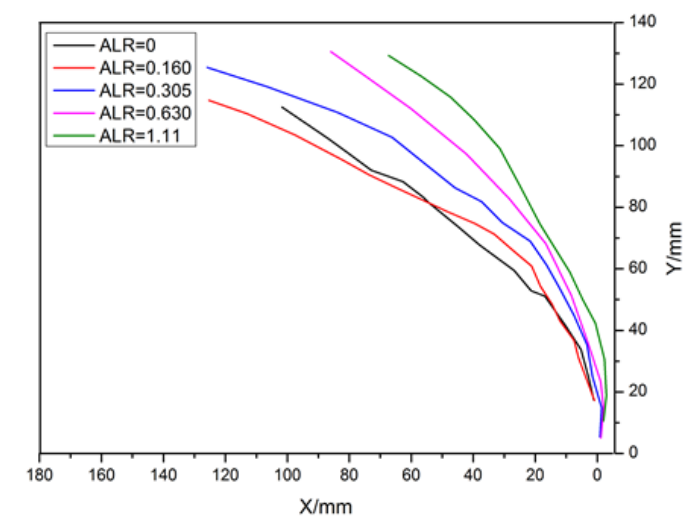

Figure 10. Comparison of jet penetration under different air-liquid ratios 


\section{Particle size analysis}

In this paper, the droplet sizes of five different positions in the liquid mist were measured. The coordinates of the five points in the coordinate system with the nozzle center as the origin were $(4,6),(4,10),(4,16),(10,3),(10,9)$ (the unit is $\mathrm{cm}$. In this paper, the Sauter diameter SMD, which can reflect the real droplet combustion property best, is used as the main parameter to measure the droplet size in the spray field. The reason why SMD cannot be measured in some conditions positions is that the number density of droplet in here is too low, which makes the particle size analyzer unable to get effective data. Taking the position of the measured point of $A L R=0.134$ shown in Figure 11 as an example, the effective data cannot be obtained because the droplet number at points 2,3 and 4 is too little.

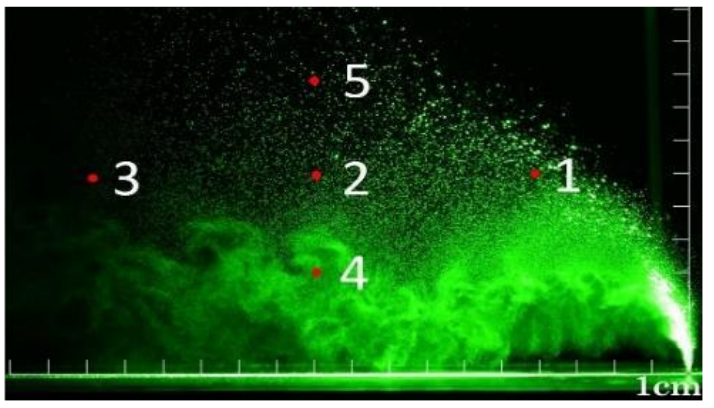

$A L R=0.630$

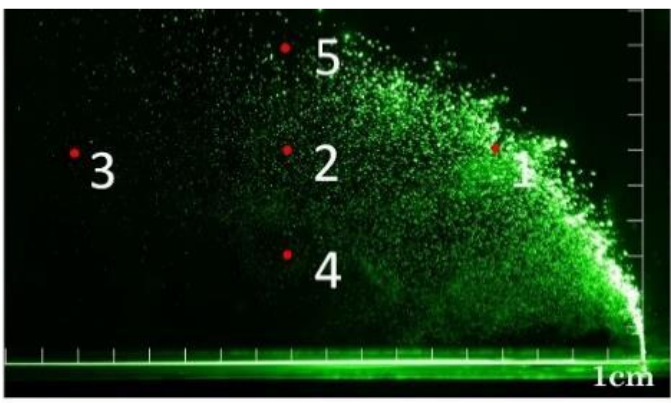

$\mathrm{ALR}=0.134$

Figure 11. SMD measuring position

Table 2 shows the SMD of five measuring points under 12 working conditions.

Table 2 SMD data of each measuring point under different jet ALR

\begin{tabular}{c|ccccc}
\hline ALR & $\begin{array}{c}\text { Position 1 } \\
(\mu m)\end{array}$ & $\begin{array}{c}\text { Position 2 } \\
(\mu m)\end{array}$ & $\begin{array}{c}\text { Position 3 } \\
(\mu m)\end{array}$ & $\begin{array}{c}\text { Position 4 } \\
(\mu m)\end{array}$ & $\begin{array}{c}\text { Position 5 } \\
(\mu m)\end{array}$ \\
\hline 0.134 & 200.208 & - & - & - & 203.041 \\
0.160 & 195.941 & - & - & - & 204.514 \\
0.174 & 191.908 & - & - & - & 196.573 \\
0.202 & 181.981 & - & - & - & 175.018 \\
0.305 & 161.427 & 67.445 & - & - & 162.431 \\
0.414 & 109.55 & 37.621 & 36.424 & - & 114.371 \\
0.488 & 89.653 & 30.966 & 33.358 & - & 73.303 \\
0.630 & 55.381 & 22.641 & 26.493 & 12.482 & 59.695 \\
0.753 & 43.504 & 18.113 & 21.886 & 11.121 & 51.339 \\
0.950 & 38.849 & 16.505 & 17.620 & 9.802 & 24.456 \\
1.11 & 28.999 & 15.049 & 14.811 & 10.088 & 33.411 \\
1.60 & 12.694 & 12.191 & 12.277 & 10.028 & 22.245
\end{tabular}

These data are made into a broken line graph (Figure 12) of particle size jet ALR.

From the SMD measurement data of different ALR, it can be seen that with the increase of annular air mass flow, the droplet size will decrease significantly.

For position 1, it represents the droplet size at the initial stage of jet breaking. At this position, the SMD of the droplet decreases from $200 \mu \mathrm{m}$ to $12.7 \mu \mathrm{m}$, which fully shows that the annular air plays an important role in the atomization of the liquid jet. The larger the ALR of the two-phase jet is, the more obvious the atomization effect is;

For position 2, when the annular air flow mass rate is low, most of the liquid flows directly along the jet trajectory above this position, so the droplet concentration at this position can not 
meet the measurement requirements. With the increase of annular air flow, the spray field begins to bifurcate. The droplets at this position are mainly larger droplets which are peeled off from the jet surface by airflow. The effect of annular air is still obvious, and the droplet size is reduced from $67.4 \mu \mathrm{m}$ to $12.2 \mu \mathrm{m}$.

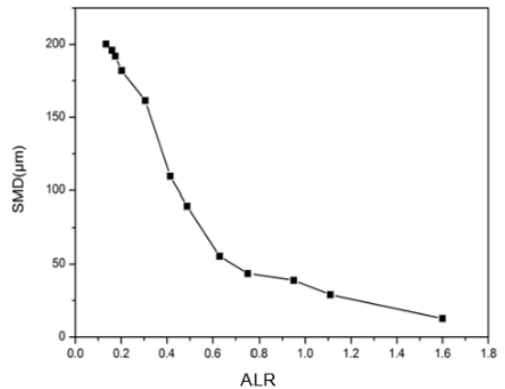

(a) Location 1

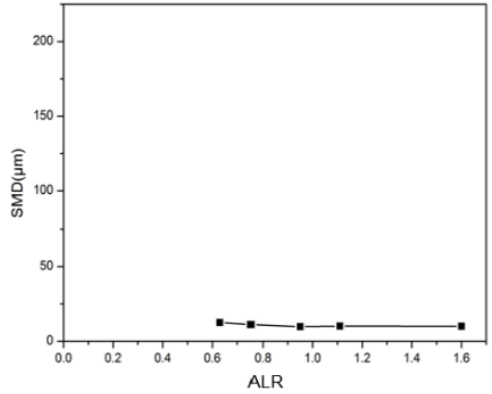

(d) Location 4

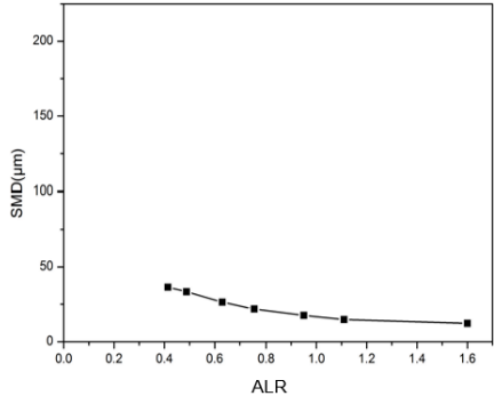

(b) Location 2

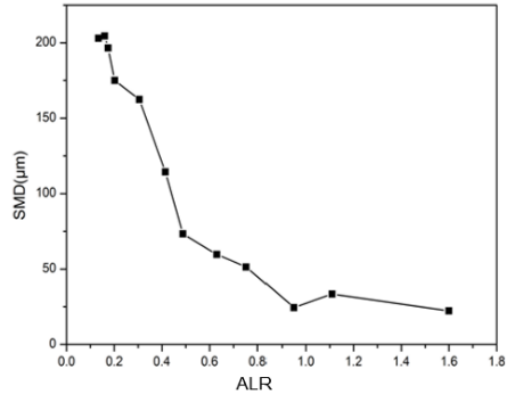

(e) Location 5

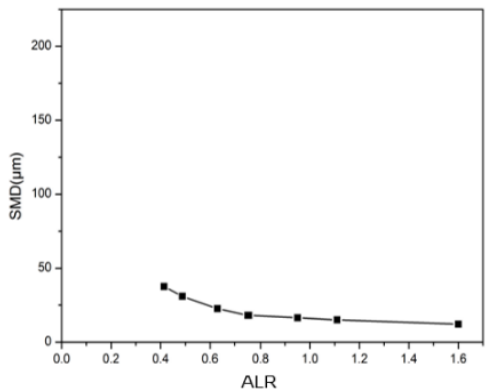

(c) Location 3

Figure 12. The change of droplet size with ALR at different measuring positions

The droplet size values of measuring point 3 and point 2 are approximately the same. Combined with the positions of the two points, it is judged that the droplets in the region where the position 3 is located are basically the droplets in the Zone III moving back here with the cross-airflow. The effect of annular air is similar to that of position 2.

The position 4 is located in the Zone IV, the droplets here are peeled off by the annular air, at the initial stage of leaving the nozzle, and flow into this area with the lateral airflow. Since the data can be measured, it has been kept at the $10 \mu \mathrm{m}$, and the trend of decreasing is not obvious, but the number of droplets increases significantly.

The Point 5 is located in the Zone II, and the droplets in this area are all the droplets with the strongest penetration ability, so it is reasonable to have the largest particle size. However, the particle size in this region is still reduced from $200 \mu \mathrm{m}$ to about $20 \mu \mathrm{m}$. it can be seen that the effect of annular air on the particle size of jet atomization is very significant.

\section{Conclusions}

In this experiment, the influence of annular air flow mass rate on the atomization of coaxial parallelflow airspray nozzle was studied by comparing the images of spray field with different ALR and the droplet size at different positions. Through this experiment, it can be concluded that the annular air can significantly enhance the atomization effect of the direct nozzle on the liquid jet.

1. The most obvious phenomenon caused by annular air is the bifurcation of liquid jet: one is the track of the original liquid jet, the stronger the penetration; the other is the small diameter droplets stripped by annular air, which are distributed in the lower part of the spray field. 
2. When the ALR is large, the area of droplet distribution enlarged due to the air-assist atomization effect.

3. Due to the existence of annular air, the droplet size is significantly reduced. In zone 1 where the change is most obvious, the droplet size drops from about $200 \mu \mathrm{m}$ to about $20 \mu \mathrm{m}$.

4. ALR makes the distribution of the liquid mist field changed, the larger the gas-liquid ratio, the more spread the liquid mist field.

\section{Acknowledgments}

This study is supported by the National Science and Technology Major Project (HT-2017III-0002-0026-002).

\section{References}

[1]Michael J. Foust, Doug Thomsen, Rick Stickles, et al. Development of the GE Aviation Low Emissions TAPS Combustor for Next Generation Aircraft Engines[C]. 50th AIAA Aerospace Sciences Meeting, 09 - 12 January, Nashville, Tennessee, 2012, 1-9.

[2]Lefebvre A H, Ballal D R. Gas Turbine Combustion[M]. Taylor \& Francis, 1999.

[3]Mongia H. TAPS: A Fourth Generation Propulsion Combustor Technology for Low Emissions[C]. AIAA International Air and Space Symposium and Exposition: The Next 100 Years, 2013.

[4]Foust M J, Thomsen D. Development of the GE aviation low emission TAPS combustor for next generation aircraft engines[R]. AIAA-2012-0936, 2012.

[5]Dhanuka S K, Driscoll J, Mongia H. Instantaneous Flow Structures in a Reacting Gas Turbine Combustor[C]. AIAA Joint Propulsion Conference \& Exhibit. 2008, 1-4.

[6]Chin J S. Study on hybrid airblast atomization[R]. AIAA 96-0406, 1996.

[7]Becker J, Hassa C. Liquid fuel placement and mixing of generic aero engine premix module at different operating conditions[J]. Journal of Engineering for Gas Turbine and Power, 1986. [8]Chi-Ming Lee, Clarence Chang, et al. NASA project develops next generation lowemissions combustor technologies[C]. 51st AIAA Aerospace Sciences Meeting, 07-10 January, Texas, 2013.

[9]Chi-Ming Lee, Clarence Chang, Stephen Kramer. NASA project develops next generation low-emissions combustor technologies[C]. 51st AIAA Aerospace Sciences Meeting, 07-10 January, Texas, 2013.

[10]Seay J, McDonell V, Samuelsen G. Atomization and dispersion from a radial airblast injector in a subsonic crossflow [R]. AIAA 95-3001.

[11]Leong M Y, McDonell V G, Samuelsen G S. Effect of ambient pressure on an airblast spray injected into a cross flow[J]. Journal of Propulsion and Power,2001,17(5).

[12]Wu P K, Kirkendall K A. Processes of liquid jets in subsonic crossflow[J]. Journal of propulsion and Power, 1997,13(1):64-73.

[13]Anubhav S, Mohan A M, et al. Airblast spray in crossflow-Structure, trajectory and droplet sizing [J]. International Journal of Multiphase Flow, (2015-72), 97 111.

[14]Anubhav S, Mohan A M. Experimental studies on evaporation of fuel droplets under forced convection using spray in crossflow methodology[J]. Fuel 164(2016)374 385. 